\title{
Alteration and primary kimberlite rock type classification for Lahtojoki kimberlite, Finland
}

\author{
Heini M. Laine ${ }^{1}$ and Hugh E. $\mathrm{O}^{\prime}$ Brien $^{2}$ \\ ${ }^{1}$ European Diamonds Plc, 22 Grosvenor Square, London W1K 6LF, UK,(heini.laine@sroy.fi) \\ ${ }^{2}$ Geological Survey of Finland, P.O. Box 96, FI-02151, Espoo, Finland
}

The economic potential of the Group I Lahtojoki kimberlite pipe, situated in Central Finland, was investigated by European Diamonds Plc during drilling and bulk sampling programs in 2004 and 2005. Drill core logging allowed discrimination of a variety of rock types, information that was used to build a geological model for the pipe, a critical step in resource mapping. However, the kimberlite is pervasively altered, and the main goal of this work was to distinguish secondary alteration effects from primary features so that grade evaluation could be correctly based on exclusively primary rock types. The bulk of Lahtojoki kimberlite is composed of diatreme facies TK and TKB (terminology according to Clement and Skinner, 1985). Two visually distinct types of TK have been observed that have been labeled as TK and SerpTK. Small volumes of HK have been observed as autoliths in TK (labeled as SerpTKauto).

In total twenty one rock samples were analyzed for stable isotopes of oxygen and carbon. These samples represent all rock type varieties observed during drill core logging. Among the rock types listed above also one sample of weathered TK and one sample of kimberlite from the bedrock/overburden interface (SED) were included. From these samples five thin sections were prepared for SEM-imaging and EDSanalysis. XRD-analysis was performed on ten samples of which five samples were also subjected to IRanalysis to clarify smectite and serpentine mineralogy. Also two additional calcite samples from a nearby kimberlite dyke were analyzed for stable isotopes $\mathrm{O}$ and $\mathrm{C}$ for reference.

According to the logging and $3 \mathrm{D}$ model generated by EDP as well as results gained in this study the emplacement of Lahtojoki kimberlite likely occurred in multiple stages related to one eruptive event, resulting in the emplacement of diatreme rock types tuffisitic kimberlite (TK) and tuffisitic kimberlite breccia (TKB). Characteristics of these rocks that suggest diatreme facies emplacement include: the absence of calcite, the abundance of microlitic diopside, and the presence of pelletal lapilli. Two types of TKBs can be distinguished: 1. Collapse breccias occurring within the kimberlite body and 2. Contact breccias that occur near the pipe-country rock contacts related to wallrock hydrofracturing 'frozen in' during pipe emplacement. TK and TKB comprise the bulk of the pipe whereas hypabyssal kimberlite (HK) is so far limited to several autolith rich zones in TK (labeled SerpTKauto). HK is distinguished from TK/TKB by having phenocrystal textures (Fig. 1) and a relatively high matrix calcite component (Fig. 2). There is no isotopic distinction between HK and TK/TKB (Fig. 3).

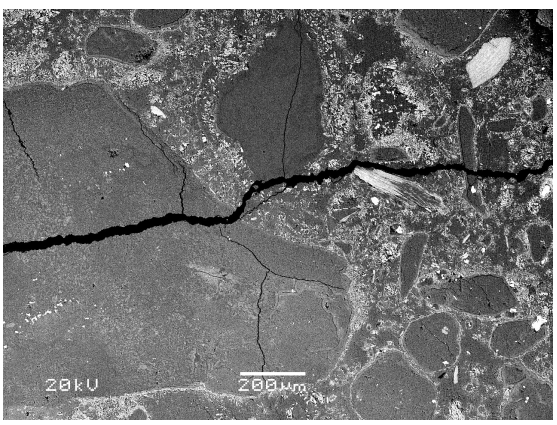

a)

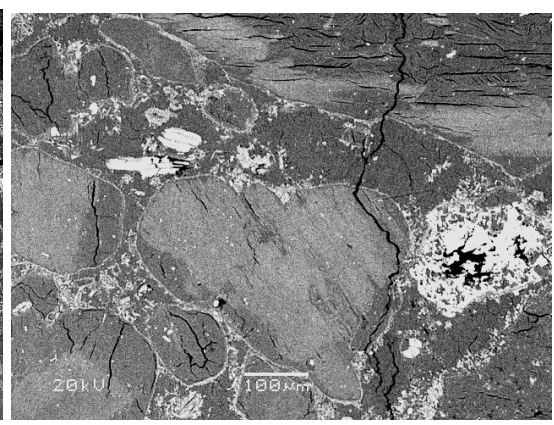

b)

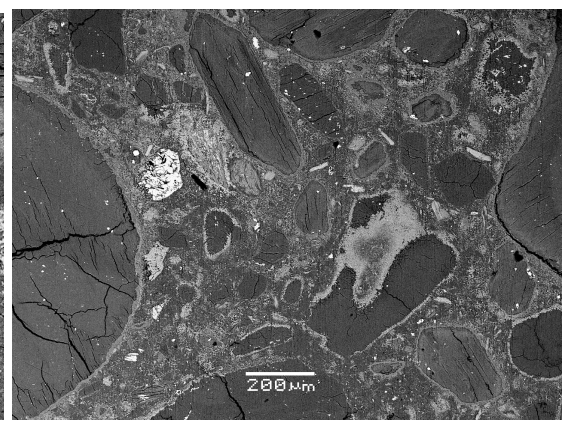

c)

Fig. 1 BSE-images show the overall textures of a) SerpTK b) TK and c) HK. Textures in a and b are very similar, whereas c shows a microphenocrystal texture. 


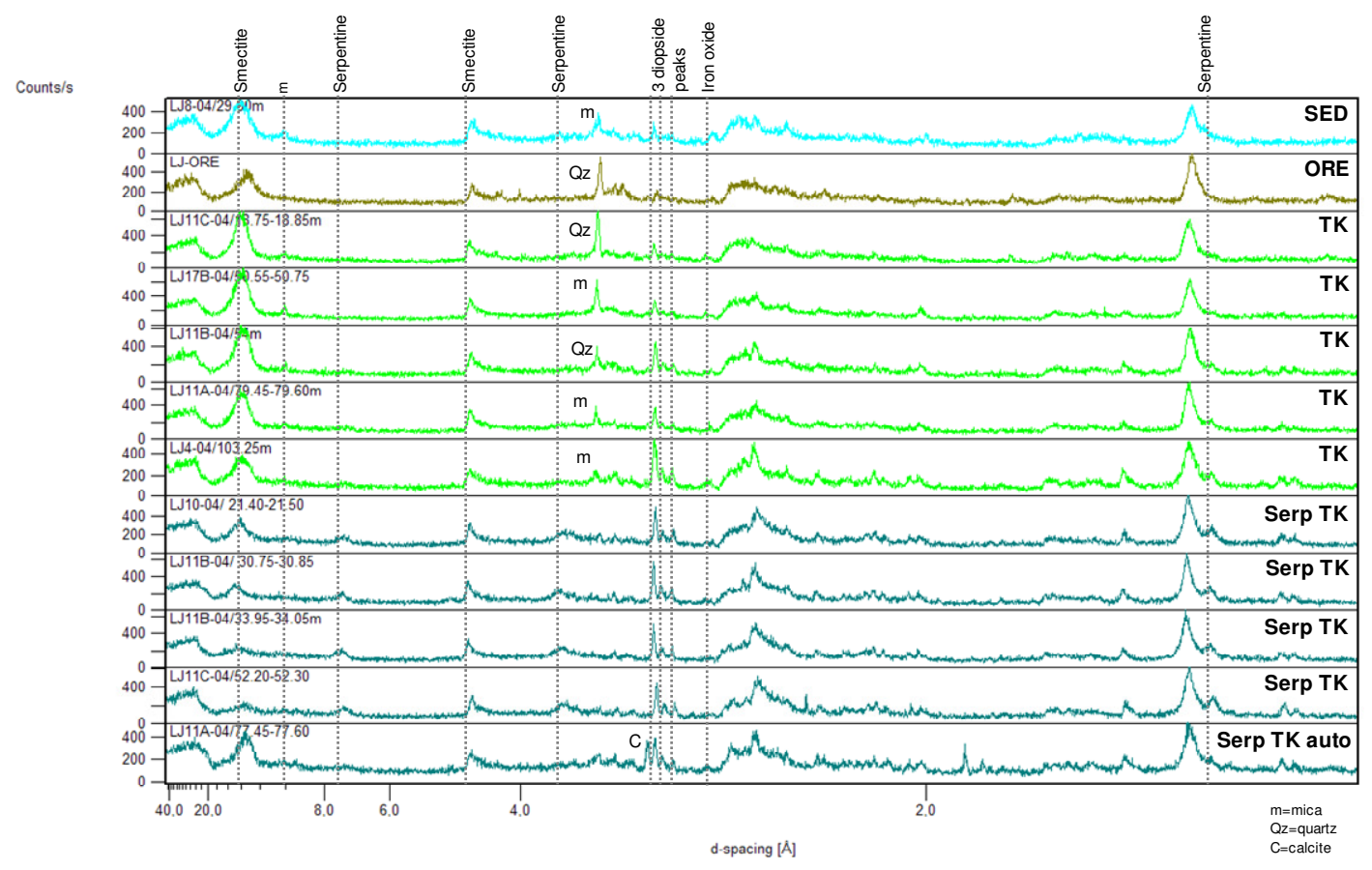

Fig. 2 XRD-results. Main peak locations for smectite, serpentine and diopside are marked with dashed lines. Serpentine is detected in SerpTK samples only (weak peak also in one TK sample). Diopside peaks are higher in serpentine bearing samples. Calcite (C) is observed only in SerpTKauto sample.

Lahtojoki kimberlite has gone through at least three types of post-emplacement alteration resulting in different matrix mineralogies (Fig. 4): 1. Serpentinization, accompanied by crystallization of microlitic diopside, occurred shortly after emplacement after cooling to $<400{ }^{\circ} \mathrm{C}$, under high water/rock ratios driven by meteoric water infiltration (Stripp et al. 2006). 2. Saponitization followed after temperatures cooled further to $\sim 70{ }^{\circ} \mathrm{C}$ and water/rock ratios dropped considerably (D'Antonio and Kristensen, 2004). This stage of kimberlite alteration (Bowen and Tuttle, 1949; Fairbairn and Robertson, 1966; Kresten, 1973) did not go to completion everywhere in the kimberlite body, which lead to formation of distinct alteration types SerpTK and TK, of which the former still contains some lizardite (Fig. 2). $\delta^{18} \mathrm{O}$ results (average 20.24 SMOW) (Fig. 3) suggest low-temperature alteration at $<100{ }^{\circ} \mathrm{C}$ in the entire kimberlite body related to this alteration event. 3. Small-scale diagenetic alteration (glauconitization) was observed on the topmost parts of the pipe related to more recent processes after erosion to the current level. Carbon isotopes map this progressive alteration process, giving $\delta^{13} \mathrm{C}$ of -2 to -4 for strongly saponitized SerpTK, -3 to -6 for thoroughly saponitized TK and -10 for glauconitized TK, alteration stages 1-3 respectively (Fig. 3). Autolith (HK) in TK falls in the range of TK. This indicates that the processes of saponitization and glauconitization have a lowering effect on the $\delta^{13} \mathrm{C}$ values of groundmass calcite. In case of saponitization this effect is rather subtle as the carbon composition still plots within the kimberlitic range -1.6 to $-10 \%$ (Baertschi, 1957; Deines and Gold, 1973; Sheppard and Dawson,
1975 among others). In the case of glauconitization the effect is more dramatic compared to the rest of the pipe and is attributed to the effect of open meteoric water circulation during alteration.

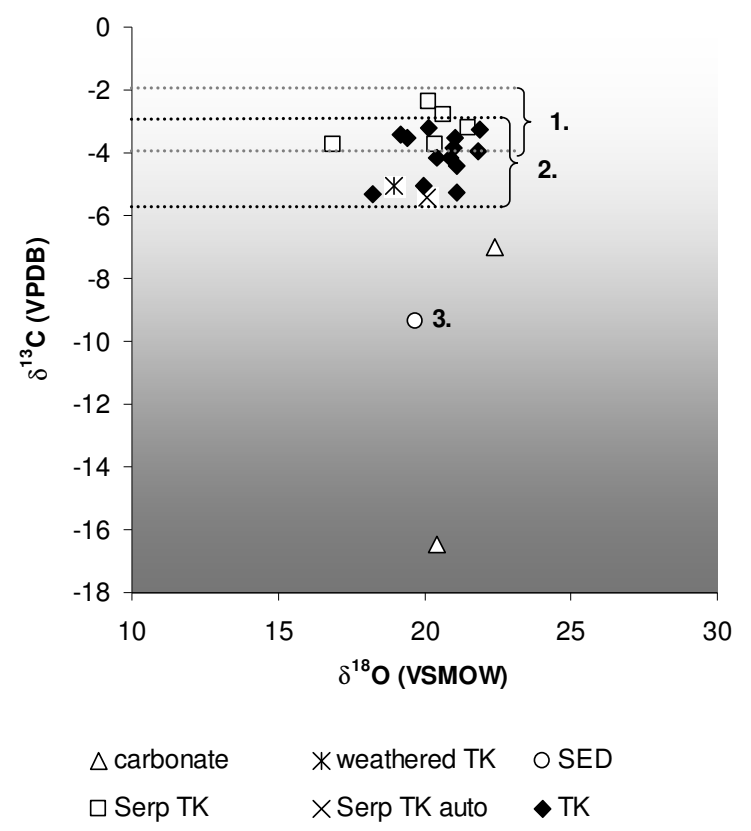

Fig. 3 Oxygen and carbon stable isotope results. Different alteration stages have been numbered in order of increasing stage of alteration: 1. Serpentinized and strongly saponitized, 2. Thoroughly saponitized, 3. Glauconitized. 


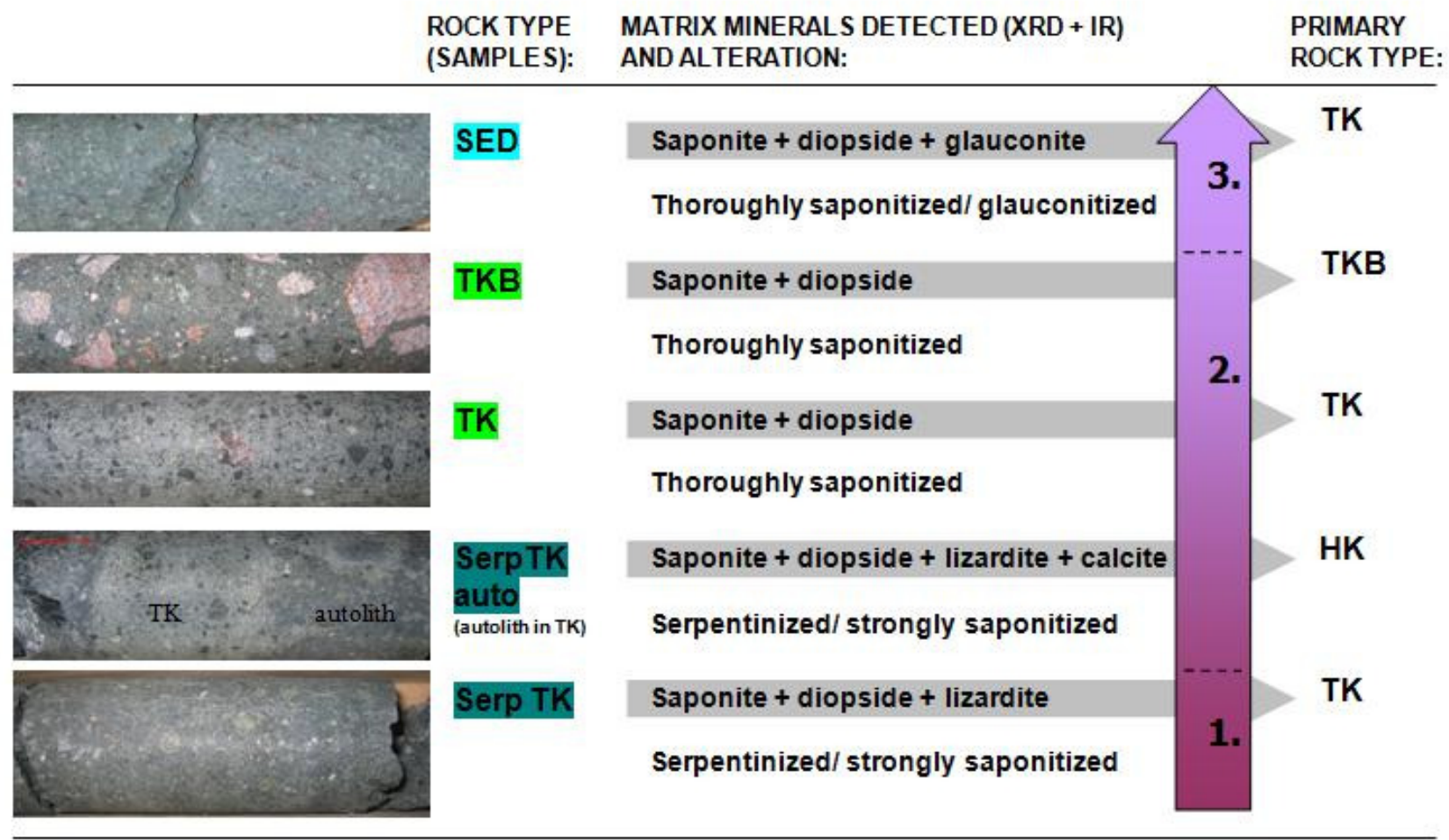

Fig. 4 Rock types, XRD- and IR-analysis results and interpreted alteration. The arrow shows the direction of progressive alteration (numbering 1-3 corresponds to that of Fig. 3).

Results from SEM imaging, EDS analysis, XRD analysis accompanied by IR analysis and stable isotope analysis of oxygen and carbon of groundmass calcite are consistent with the visually distinct rock types TK and SerpTK being simply different alteration stages of the same rock type. In TK, saponite dominates, with remnant patches of serpentine occurring predominantly in olivine pseudomorphs whereas in SerpTK primary serpentine occurs along with saponite both in pseudomorphs and in the rock matrix. An interesting feature of the alteration distribution is that the least altered rock type, SerpTK, is rather uniformly located near the pipe edges. This may suggest centrally focused flow in the late stage hydrothermal circulation pattern, but a detailed model requires further study.

As for the main goal of the project, it is clear that the distinction between the main rock types is due to secondary alteration, and that the most important geological diamond grade control in Lahtojoki kimberlite is country rock xenolith dilution.

\section{References}

Bowen, N.L., Tuttle, O.F., 1949. The system MgO-SiO ${ }_{2}^{-}$ $\mathrm{H}_{2} \mathrm{O}$. Geological Society of America Bulletin, 60, 439460.

D’Antonio, M., Kristensen, M.B., 2004. Hydrothermal alteration of oceanic crust in the West Philippine Sea Basin (Ocean Drilling Program Leg 195, site 1202): inferences from a mineral chemistry investigation. Mineralogy and Petrology, 83, 87-112.

Clement, C.R., Skinner, E.M.W., 1985. A textural-genetic classification of kimberlites. Transvaal Geological Society of South Africa, 88, 403-409.

Baertschi, P., 1957. Messung und Detung relativer Haufigkeitsvariationen von $18 \mathrm{O}$ und $13 \mathrm{C}$ in Karbonatgesteinen und Mineralien. Schweizerische Mineralogische und Petrographische Mitteilungen, 37, 74-152.

Deines, P., Gold, D.P., 1973. The isotopic composition of carbonatite and kimberlite carbonates and their bearing on the isotopic composition of deep-seated carbon. Geochima Cosmochima Acta, 37, 1709-1733.

Fairbairn, P.E., Robertson, R.M.S., 1966. Stages in the tropical weathering of kimberlite. Clay Minerals, 6, 351370.

Kresten, P., 1973. The coating on kimberlitic zircons: A preliminary study. In: Nixon, P.H. (Ed.) Lesotho Kimberlites, LNDC, Maseru, Lesotho, 220-223.

Sheppard, S.M.F., Dawson, J.B., 1975. Hydrogen, carbon and oxygen isotope studies of megacryst and matrix minerals from Lesothan and South African kimberlites. Physics and Chemistry of the Earth, 9, 747-763.

Stripp, G.R., Field, M., Schumacher, J.C., Sparks, R.S.J., Cressey, G., 2006. Post-emplacement serpentinization and related hydrothermal metamorphism in a kimberlite from Venetia, South Africa. Journal of Metamorphic Geology, 24, 515-534. 